
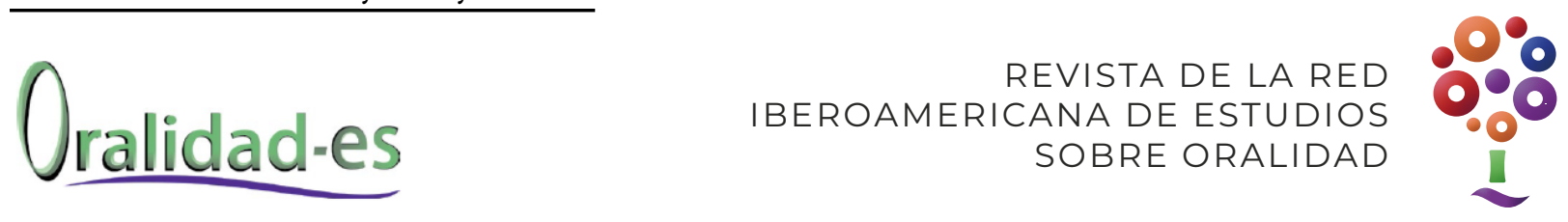

\title{
Conflicto armado y transformación cultural en los cantos de tambora del río Magdalena
}

\author{
Los casos de Grilbin Revel y Martina Camargo \\ Armed conflict and cultural transformation in the tambora songs \\ of the Magdalena river \\ The cases of Grilbin Revel and Martina Camardo
}

\author{
David Lara-Ramos \\ dlarar@unicartagena.edu.co; \\ david28lara@gmail.com \\ Universidad de Cartagena, Colombia
}

Lara-Ramos, D. (2018). Conflicto armado y transformación cultural en los cantos de tambora del río Magdalena. Los casos de Grilbin Revel y Martina Camargo. Oralidad-es, 4, 1-13. https://revistaoralidad-es.com/index.php/ro-es/article/ view/104/75

Fecha de recepción: 2 de junio de 2018 / Fecha de aprobación: 24 de noviembre de 2018

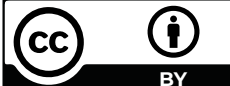




\section{Resumen}

El conflicto armado en Colombia se ha concentrado, especialmente, en porciones de territorio rurales. Ha sido una geografía que hemos conocido por ataques a sus poblaciones, desplazamiento, masacres y desaparición forzada, entre otras violaciones a sus derechos. Este trabajo se ocupa de la región de Loba, en la que el conflicto armado ha entregado otras visiones de la vida, y los compositores de la región las han llevado a las letras de sus canciones de tambora, expresión musical afro que se concentra, especialmente, en los municipios de Hatillo de Loba, Barranco de Loba y San Martín de Loba. A partir de los testimonios del maestro Grilbin Revel Sáez y de la maestra Martina Camargo, voz emblemática de los aires de tambora, se analizan sus formas de componer, sus convivencias con el conflicto y sus relaciones con su vida, enmarcado en las actividades propias de un territorio ribereño.

Palabras clave

Conflicto armado colombiano; música y cultura; tambora; aires de tambora; composiciones; letras de canciones

\section{Abstract}

The armed conflict in Colombia has been concentrated in rural areas. We have known about these areas due to attacks on the rural community, missing people reports, and other human rights violations. This paper deals specifically with the Loba region. In this region, the conflict has created a completely altered version of life and composers in the region have manifested this in their Tambora songs, a type of Afro musical expression which is mainly concentrated in the Hatillo de Loba, Barranco de Loba, and San Martin de Loba municipalities. Based on the testimonies given by Grilbin Revel and Martina Camargo, an emblematic voice of Tambora music, their compositions are analyzed to understand the coexistence and relationship between the armed conflict and their life close to the Magdalena river.

Key words:

Armed conflict; music and culture; tambora music; lyric composition 


\section{Introducción}

Este trabajo en toda su magnitud muestra casos de autores, músicos y compositores que viven o han vivido en zonas donde se ha escenificado el conflicto armado en el Caribe colombiano. Se ha ocupado de las regiones de Montes de María, Región de Loba y Guacamayal en el Magdalena, en las que el autor establece una relación directa con los músicos y, a través de entrevistas, va narrando cómo ha sido crear o realizar sus prácticas culturales en esa zona de violencia.

Los cantantes y compositores Grilbin Revel y Martina Camargo han vivido sobre la margen sur del denominado Brazo de Loba, en el río Magdalena. Una zona en la que el conflicto armado hizo presencia a finales de los años 60 cuando se ubican en la zona grupos del llamado Ejército Popular de Liberación, EPL, que comenzó a transitar por la región. Para mediados de los años 90, comienzan a hacer presencia miembros de grupos paramilitares que despojaron las tierras de propiedad de don Cayetano Camargo, padre de Martina. Ambos compositores estudiados en este artículo narran los hostigamientos constantes sufridos cuando los grupos armados intentaron entrar tanto a San Martín como a Barranco de Loba.

Es un trabajo que se ha venido escribiendo y documentando desde 2015. Además de los relatos expuestos en este artículo, está el caso del maestro gaitero Félix Contreras, de la población de El Piñal, en la región de Montes de María, cuya finca estaba en un corredor que comunicaba, hacia el norte, con las poblaciones del departamento de Bolívar, y que fue usado por militares y por fuerzas armadas al margen de la ley, guerrilleros y paramilitares, y llegó un momento en que su práctica cultural, la interpretación de la gaita corta, tuvo que suspenderla.

Otra de las regiones estudiadas en la Región de Loba es la conformada por Hatillo de Loba, Barranco de Loba, y San Martín de Loba. Allí se estudió a las cantadoras Delsy Gil, quien luego de la muerte de su padre, el tamborero Casildo Gil, se ha dedicado al canto y a difundir las composiciones de su progenitor. También el caso de la cantadora Martina Camargo, quien con su trabajo de 30 años, ha sabido mostrar su tradición musical al igual que trabajar por la defensa de la naturaleza y por el cuidado permanente del río Magdalena.

Presentaremos aquí dos casos de artistas que viven en la Región de Loba, en donde se encuentran los municipios de Hatillo de Loba, San Martín de Loba y Barranco de Loba. El nombre de la región es tomado del llamado brazo de Loba, tramo del río Magdalena. La región de Loba fue habitada, antes de la llegada de los españoles, por indígenas chimilas y malibúes, los cuales fueron aniquilados por los españoles. Es una región rica en oro, ganadería y pesca. En el siglo XVII se registró una buena concentración de afros que lograron zafarse del yugo de la esclavización y conformaron poblaciones en cercanía de lo que hoy es San Martín y Barranco de Loba, como el palenque de San Antonio, Norosí o Tiquisio. En medio de una tradición musicalmente afro, como es la tambora, y con influencia mestizas en sus cantos y estructuras de composición han creado sus obras musicales Grilbin Revel y el de Martina Camargo, casos que analizaremos a continuación. 


\section{Grilbin Revel Sáenz: "La cumbia es un cielo para miti- gar las penas"}

El compositor Grilbin Revel Sáenz (Figura 1) cree que la cumbia es un cielo donde el espíritu mitiga las penas. Es más que los versos que producen felicidad en quien la canta; más que los bríos de aquellos que danzan y gozan su melodía. La cumbia es para Grilbin Revel la exaltación de los ríos, la siembra, el campo y la pesca. Son los silencios de una ciénaga, los cantos del monte o la selva, como a veces él mismo lo refiere.

Esos paisajes que describe son los donde nació y se crió Grilbin Revel. Un músico y compositor, del municipio de Barranco de Loba, a orillas del río Magdalena. Es el lugar donde aprendió a pescar al lado de su padre, a quien describe como un ser trabajador, alegre, que improvisa y canta versos mientras realiza sus extenuantes jornadas de pesca y de campo.

Cuando Grilbin era un niño, recuerda que su padre lo llevó a pescar.

Él me acomodaba en el fondo de la piragua -cuenta-y me quedaba quietecito. Mientras tiraba su atarraya, yo miraba la luna $y$ las estrellas. Eran noches alumbradas por la luna; se escuchaba el zumbar de la brisa, los golpes del agua debajo de la embarcación, y los cantos del viejo Julio, mi papá, como si quisiera ahuyentar el silencio (G. Revel, comunicación personal, abril, 12 de 2015).

Esas experiencias de hombre de río fueron construyendo la personalidad y sensibilidades de un compositor que le canta al paisaje, a las vivencias de ese hombre alegre, verseador, de atarraya, piragua y canalete.

Cuando Grilbin tenía diecisiete años, hizo su primera canción. Un vallenato que tituló Esa muchachita, dedicada a una vecina de la que se enamoró; con quien vive actualmente. Con sus
Figura 1.

Griblin Revel Sáenz.

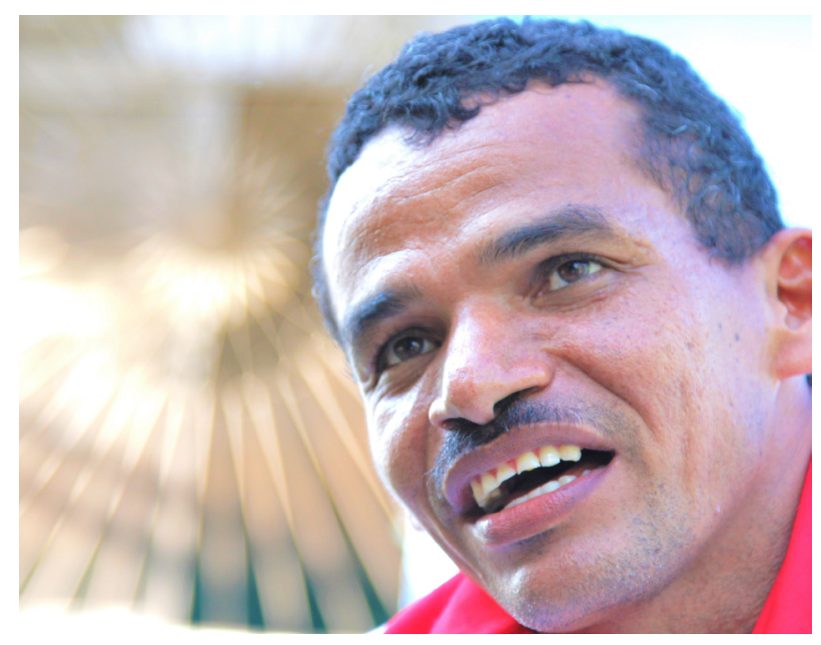

Foto de David Lara Ramos.

canciones no solo conquistó a su mujer, también ha ganado más de 15 festivales de la región, en lugares como Hatillo de Loba, El Peñón y Tamalameque. En cinco oportunidades logró el primer puesto en la modalidad de canción inédita en el Festival de la Tambora de San Martín, un género que identifica la región. En el Festival de la Cumbia de El Banco, Grilbin participó por primera vez en 2011, con la canción Réplica, que fue escogida entre las cinco mejores de esa versión del Festival. Al año siguiente (2012), presentó el tema Gestación, que resultó ganador.

El tema Gestación explora los orígenes indios y negros de la cumbia. Contempla la relación entre las gaitas y los cueros del tambor. Más allá de la simplificación triétnica, Revel construye poesía para contarnos esa realidad de mixturas, desde su óptica de compositor y verseador. El tema nos presenta una crónica libre de las relaciones entre indios y afros, en medio de la música y la fiesta. Acá su letra:

Llévame río Magdalenal Al sol de su nacimiento/ Tráeme mensajes del tiempo/ De aquella fuente primera/ Cuando al calor de las velas/Se armaba la algarabía/ Y los tambores crujian/ Cual la voz del preso imploral A Dios la brillante auroral Desatarse 
de sus ligas// El indio y el negro lloran/ Juntos su melancolial/ Preciso es para su cuna/ El Caribe sol radiante/ Yo fui su camino errante/ Dijo el río con sus espumas/ Pa' no alargarte la cumbia/ La trajo un negro en su pecho/ $Y$ agregó más sentimiento/ Un indio que sí sabial Adornar las melodias/ Que a ratos cantaba el negro// Y fue hermosa la armonía/ De la gaita con los cueros/Por los montes y mis playas/Labriegos y pescadores/Se forjaron trovadores/ Pa la reina y soberana/ De humilde casta $y$ hermana/ Flor de los bailes cantaos/ Que por mis aguas viajaron/Alimentando los sueños// Que al brote de indios y negros/ en los cueros/Los azotes despiadados//.

En 2013, Grilbin Revel volvió a ganar con el tema Pareja fecunda, un homenaje a los maestros José Barros, Adolfo Pacheco y Andrés Landero. Una letra que, como se ve en muchos festivales de la región, busca entregar un homenaje a los maestros de la composición y el canto, asegurando así referentes que son de rápida recordación para los jurados que eligen y el público que aclama. A pesar de los trofeos, diplomas y reconocimientos que hoy adornan los espacios de su casa en Barranco de Loba, a Grilbin le importa más que el público escuche las historias que él presenta en sus letras. Le interesa que la gente se dé cuenta de la belleza de su región, de la riqueza cultural que poseen y de los recursos naturales que deben cuidar y proteger. En otras palabras, su música es un medio para reconocer y difundir su territorio. Ese territorio que se fue llenado de actores violentos, guerrillas, paramilitares y actores armados estatales, que en algunos actos violentos actuaron en alianza con grupos paramilitares, en especial durante el período de recrudecimiento de la violencia paramilitar, años 1997-2005. De esa manera, esa cruda, cruel realidad que se vive, se expresa a través de las letras de canciones, como una forma de narrar esos pasajes que la guerra aporta a sus cantos.

En los cantos de Grilbin Revel, las temáticas referidas a la violencia tienen dos facturas muy marcadas. La primera, es directa y sin alegorías. Es el caso del tema Tirense al suelo, en ritmo de berroche. Un tema que surge de una expresión popular "Tírense al suelo", que se usa cuando ocurre algún hecho inesperado, en especial aquellos en los que se escuchan armas de fuego sin conocer las razones. Es una consigna que busca la protección de la vida en territorios en los que en muchas ocasiones no se sabe de dónde o quién es el actor armado que dispara o inicia una contienda.

La letra del tema Tirense al suelo es como sigue:

Hijos, tírense al suelo/ que esto se va a calentar/ la tropa viene subiendo/y los del monte en tierra están// Hijos, tírense al suelo/ que el diablo será el partero/ hijos, tírense al suelo/ que el que paga siempre es el pueblo/ hijos, tírense al suelo/ las puertas ya están cerradas/ hijos, tirense al suelo/ aunque no aguanten las balas/ hijos, tirense al suelo/ y quiénes serán los buenos/ hijos, tírense al suelo/sabrá un brujo y Dios del cielo//

Se desataron los truenos y no es por la tempestad/ el río escupiendo torpedos/balas vienen, balas van/ hijos tirense al suelo...// $P a$ 'dónde agarró mi abuelal que no me acompaña ya/ la aturdió la balaceral y salió a la calle a gritar/ hijos tírense al suelo...

La segunda forma que Grilbin escoge es la narración de una historia cotidiana que de manera esópica, mimética, contiene pensadas veladuras para ocultar trágicos hechos ocurridos en la región. Es el caso de la canción en ritmo de chalupa titulada Los zorros. Un tema que usa las relaciones entre los animales para escenificar las acciones de los actores armados en la región. La letra expresa:

Los bribones de la esquina ya se juntaron todos/ aseguren las gallinas y aseguren los pollos/ conformando la pandilla, están unos 
cuantos zorros/los que saltan paredillas y siempre hacen barrejobo (se llevan todo)/ cuidado con los zorros/ coro: que se roban las gallinas $[. ..] / /$.

Grilbin Revel terminó académicamente la carrera de Ingeniería Civil en la Universidad de Cartagena. Hoy es docente de matemáticas en el corregimiento de Los Cerritos, a unos 40 minutos en lancha desde Barranco de Loba. Los Cerritos es un pueblo rodeado de ciénagas, que vive de la pesca y la agricultura. A Barranco de Loba vuelve cada fin de semana a reencontrarse con su familia, sus libros de poesía, su música y una vieja guitarra que es el instrumento que usa para componer las melodías de sus temas.

Para él, esos son momentos efímeros, pero la realidad de los artistas como él, que a pesar de su talento no han grabado un álbum decoroso, lo llevó a componer con su guitarra un paseo vallenato que cuenta cómo se siente, lo poco que se valoran las músicas tradicionales de la región. Es un clamor para que los temas que son el reflejo del patrimonio musical de toda una zona, como la región de Las Lobas, no solo ganen en festivales sino que también sean grabados y promocionados. Este tema es también un homenaje al maestro Ángel María Villafañe, quien a sus 84 años, con una vida dedicada al folclor y a la cultura de la región, no tiene un trabajo discográfico en su larga trayectoria como cantante y compositor. Grilbin, más que un discurso sobre ese hecho, prefirió escribir una canción que aún espera entrar a un estudio de grabación:

De donde soy compadre/ de donde yo soy compadre/ También nacen canciones sentidas/ Como en la región del Valle, del Magdalena o de La Guajira/ Versos en todos los aires/ Como lo son los del maestro Ángel Villa/ Pero como nadie sabe/ Se mueren con quien las hacen/ $Y$ en sus gavetas se arruinan/ Pero como nadie sabe/ se mueren con quien las hacen/ y en sus gavetas se arruinan//.
No soy gran compositor pero a veces también me sale una poesíal Tampoco soy ruiseñor pero tengo momentos en que mi voz afinal $Y$ mi guitarra se inspiral se adorna tal como nacen los versos del alma mía/ Y mi guitarra se inspira/ se adorna tal como nacen los versos del alma mía// Cantaré y han de gustarle/ Cantaré y han de gustarle/ Las canciones de la tierra mía/ Que también son agradables/ De autores con gran categoría,/ Quizá no tan admirables como Escalona o Freddy Molina/ Pero tienen en su sangrel Talento para expresarles sus sentimientos en rima/ Pero tienen en su sangre/ talento para expresarles sus sentimientos y rimas.// Que nuestro hermoso folclor traspase la región se escuche en todas partes/Y compita con honor el alegre tambor con lo mejor Del Valle/ Canta, Barranco, no calles/ Aunque se ignoren las artes en todo el sur de Bolivarl Canta, Barranco, no calles, aunque se ignoren las artes en todo el sur de Bolivar//. 


\section{Martina Camargo: "el mejor camino para llegar a la paz es el arte..."}

Martina Camargo (Figura 2) lleva 30 años dedicada a los cantos de tambora. Una expresión afromestiza, que se ejecuta con tambor alegre, al que en San Martín llaman currulao, y la tambora, que va marcando y acompasando la melodía. La voz principal, en este caso la de Martina Camargo, es acompañada de un gran número de mujeres que hacen los coros. Los cantos de tambora son responsoriales. Su estructura está marcada por estrofas en versos consonantes o asonantes que son respondidos por el coro. Los coros son estribillos pegajosos, de uno o dos versos, que se repiten a lo largo de la canción. Los cantos y coros son el aporte melódico de la canción. La tambora es una expresión musical que hace parte de los llamados bailes canta'os, todos responsoriales, que se cantan y se bailan al mismo tiempo, regularmente en ruedas que se conforman alrededor de los músicos, donde se improvisan versos.

La tradición de la tambora se pierde en el tiempo, y las nuevas generaciones, como el caso de Martina Camargo, continúa una tradición familiar que ahora ella lidera y enriquece con sus nuevas composiciones.

Martina Camargo es la intérprete de este género más conocida en Colombia y en el exterior. Ha grabado cinco álbumes, algo realmente destacable, teniendo en cuenta que los músicos tradicionales como ella no alcanzan a grabar de manera periódica (Figura 3). Su carrera ha sido destacada y constante. Ha hecho un valioso aporte al repertorio de los aires de tambora desde que se subió a la tarima en 1989 alentada por su padre. Desde ese entonces, Martina no ha dejado de cantar, entregando en sus trabajos discográficos una rica tradición en la que siempre incluye temas originales de su padre.
Imágen 2.

Martina Camargo.

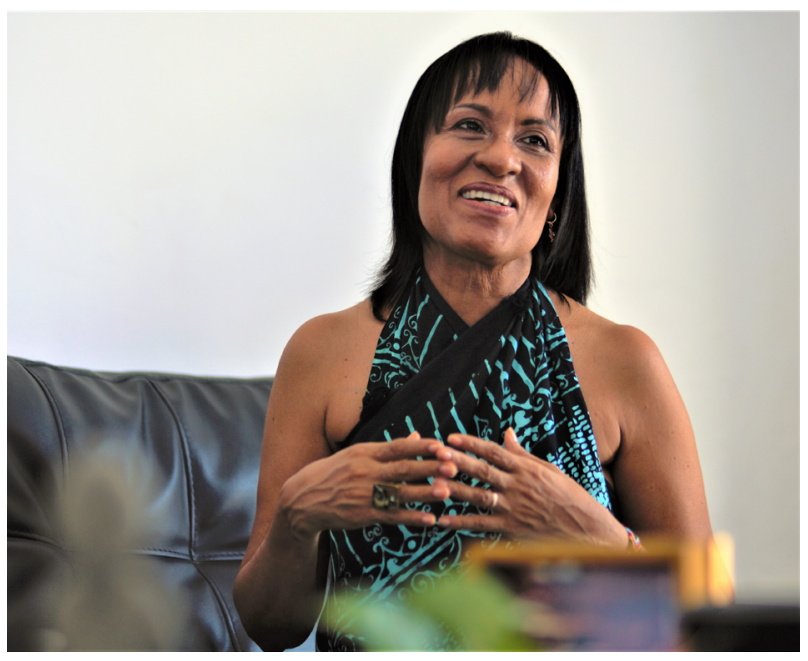

Foto de David Lara Ramos.

En 2018, Martina presentó su álbum Paisaje en tambora, en cuyas letras destaca la tradición del río y continúa con la lucha por la preservación de ese paisaje que le dio la vida, afianzada al legado de su padre, quien desde los años sesenta ya hablaba y componía letras relacionadas con el cuidado de las riberas y del lecho del Magdalena.

La fecha que marca su carrera es 1989, año en que se subió por primera vez a la tarima del Festival de tambora de San Martín de Loba. Es una fecha que ella misma ha fijado como el

\section{Imágen 3.}

Martina Camargo.

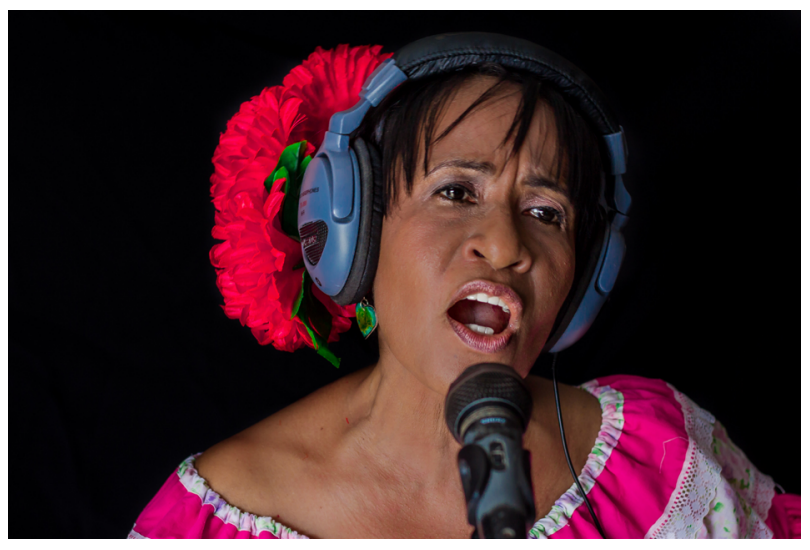

Foto de David Lara Ramos. 
nacimiento de una nueva cantadora. Si tomamos como referencia esa fecha, estaríamos simplificando un complejo entramado de experiencias culturales y vivencias que convirtieron a Martina en la mujer que es hoy, en el sujeto cultural que carga su tradición como un ideal de su existencia.

Si pensamos en aquel lejano día y nos quedamos únicamente con sus versos sobre la tarima, dejaríamos de lado sus vivencias de canoas frente al río Magdalena; borraríamos los días de subiendas de bocachico grabados en su mente, desconoceríamos los aportes de su padre Cayetano para que entonara con nuevos bríos temas como Las olas de la mar, Me robaste el sueño, La pluma, El mohán, entre otras. Desecharíamos las rondas infantiles que ella iniciaba en las tardes, y terminaba al anochecer como una tradición que daba luz a esas noches sin electricidad, llena de estribillos y movimientos que Martina conservó en su memoria y plasmó en su trabajo discográfico Cantos y juegos a ritmos de tambora.

Negaríamos también su lucha por la preservación de esos paisajes de garzas blancas, patos cuchara y yuyos que atraviesan libres la magnitud del cielo del Magdalena, que ella narró y sigue narrando en sus obras. La obra Paisaje divino, de su autoría, narra vivencias en el río, en el que traza discursos que claman y proclaman un mejor futuro para el Magdalena:

¡Oye, río Magdalenal aqui te canta la Sirena!/ Eres paisaje divino, / hermosa naturaleza, / como fue Dios que te hizo, por eso es que embelesas.// Yo te canto, yo te canto/ no dejaré de cantarte, / yo te canto, yo te canto, / queremos recuperarte.// En tus orillas se siembra/ cultivo de pancoger, / si tú desaparecieras/ qué podríamos comer.//

Por qué tanta necedad, / es un raro proceder, / si tú desaparecieras/ qué podríamos comer. // Quiero contarte mis penas/ porque eres muy discreto, / en tus aguas muy profundas/ se guardan tantos secretos.// Eres río imponente, / eres río que fascinas, / en noches de luna llenal tus aguas se ven tranquilas. Cuando veo pasar tus aguas/ siento que vas reprochando/ la imprudencia del hombre/ que te sigue irrespetando.// ¡Oye, sol de la mañana!/ ¡Cómo tú alivias mis penas!, / jcómo proyectas tus rayos/ sobre el río Magdalena!

A pesar de haber vivido desde niña en San Martín de Loba y sufrir muy de cerca los atropellos y despojos de tierras, por parte de los paramilitares y la guerrilla, no se aprecia en las letras de sus canciones una marcada tendencia a referirse a los hechos de violencia. Las veladuras son constantes, pero su discurso, cuando se tiene la oportunidad de entrevistarla, es fuerte y determinado:

Nosotros vivimos la violencia desde niña, uno se acuerda de cosas, ya mayor, vi el sufrimiento de uno de mis hermanos a quien los paramilitares amenazaron y luego lo despojaron de las tierras, eran las tierras de mi papá, todo eso se perdió. He sido muy prudente en mis canciones con los temas de la violencia, pero eso no quiere decir que no la haya sufrido, lo que pasa también es que tengo otras luchas, la lucha por la preservación de la naturaleza, la lucha por la tradición musical, por las costumbres y juegos de niña que yo tuve, pero la violencia en San Martín fue atroz, y la viví muy de cerca (M. Camargo, comunicación personal, junio, 14 de 2017)

Prudencia es la palabra que usa Martina. Si volvemos a la canción Paisaje divino, arriba descrita, vemos unos versos en los que ella canta: "Quiero contarte mis penas/ porque eres muy discreto, / en tus aguas muy profundas/ se guardan tantos secretos.//"

Esos tantos secretos - me contó Martina-, son los hechos de violencia y muerte que han tenido al río como escenario. Son los muertos arrojados a su cauce, son los N.N. enterrados en los cementerios de poblaciones ribereñas. 
Es la sangre y el dolor de miles de campesinos que tienen al Magdalena como lugar de vida y encuentro, de trabajo, de movilización.

El nombre de Martina honra a San Martín de Loba, patrono del pueblo. Un santo milagroso con un poder sanador que sigue extendiéndose por todo el territorio. La misma Martina repite que ella es también un milagro, una narración que exige sus propias palabras:

Mi mamá tenía muchas dificultades en su embarazo y le hicieron la petición a San Martín para que ella no tuviera problemas. El médico del pueblo, el doctor Dolores Arzuza, viendo las dificultades, dijo que debían trasladarla al médico oficial, al del puesto de salud, porque él no daba garantías y no se comprometía con el embarazo. Mi mamá fue remitida al Puesto de Salud, y el dictamen del doctor Marrugo era que a la criatura tenian que sacarla por parte, es decir desmembrada, eso quería decir matarme para salvar a mi mamá. Mi papá, Cayetano Camargo, inconforme con ese dictamen, consultó a un grupo de sacerdotes amigos de la familia. Ellos dijeron que no estaban de acuerdo con el dictamen, que tenían que hacer lo posible para darles vida a las dos, y se siguió con el embarazo. El día del parto, a mi mamá le dan los dolores en la noche, se aproximaba una tempestad; mi papá le solicitó los servicios al lanchero del pueblo para hacer un viaje expreso a El Banco, Magdalena; en esa época, no había ni carro, ni ambulancia, eran caminos reales, trochas. El señor de la lancha le cobró cinco pesos, por el servicio expreso, y mi papá no los tenía. A pesar de que era familiar, le dijo que no le rebajaba ni un peso, que esos eran los momentos que él tenía que aprovechar (M. Camargo, comunicación personal, junio, 14 de 2017).
Martina Camargo cuenta que el dicho "Estos son los momentos que se aprovechan, dijo Nieves Márquez" (nombre de aquel lanchero), quedó como parte de la familia y es hoy usado como frase comodín ante situaciones adversas en las que alguien toma ventaja.

Entonces - continúa Martina-, mi papá cogió una hamaca, organizaron a mi mamá, $y$ se fueron por el camino del rí, hasta llegar al puerto Come Miel, eso son como dos kilómetros, en medio de oscuridad y bajo tempestad. Por este suceso, mis abuelos y los de la cuadra me bautizaron como "Martina Carrera”. Y ahí esperaron, hasta que pasó una lancha y se embarcaron (M. Camargo, comunicación personal, junio, 14 de 2017).

El relato sobre las dificultades de su nacimiento, la relación de su nombre con el patrono del pueblo como agradecimiento por el milagro de su vida, y la coherencia con que defiende el legado de su padre son tres situaciones que confirman su aptitud misional hacia propósitos superiores, que se concentran en el respeto por la tradición musical y defensa del territorio que ella refleja en su composición Paisaje divino.

Ese tema -explica Martina Camargo- se iba a llamar río Magdalena, pero a medida que iba componiendo y puliendo los versos me di cuenta que no solo estaba el río, estaban sus paisajes, sus aves, los sembrados, estaba su gente, y por supuesto también estaban sus problemas, la minería que ha destruido cuerpos completos de agua. Estaban también sus muertos. Ha habido mucho dolor por causa de actores armados en todos estos pueblos de la ribera, asi que decidi cambiarle de nombre por uno que abarcara todo ese paisaje divino que es mi región de Loba ( $M$. Camargo, comunicación personal, junio, 14 de 2017).

Desde niña, Martina Camargo estuvo involucrada en las tradiciones festivas y culturares de su pueblo, siempre de la mano de su padre Cayeta- 
no Camargo, como guía de sus primeras presentaciones y de sus posteriores trabajos musicales, en los que Martina Camargo siempre incluye letras de su padre.

La tradición cultural de Martina Camargo traza conexiones familiares extensas, que son prueba de una herencia inmaterial que se ha perpetuado con el tiempo. Martina Camargo lo expresa de la siguiente manera:

Mi familia estuvo siempre con la tambora, mi papá Cayetano y su hermana Serafina Camargo que eran cantadores, bailadores $y$ compositores. Aminta Marín, hija de mi tía, Serafina Camargo, sobrina de mi papá y prima hermana mía, cantadora. Juan Esteban Centeno, ejecutaba la tambora, hermano de mi abuelo materno. Mi abuela materna, Nicolasa Centeno, cantadora. La hermana de mi abuela materna, mi tía Catalina Puerta, bailadora, las hijas de Paulino Camargo, hermano de mi papá, Melba Camargo, Asteria Camargo, cantadoras y compositoras.

Los hijos de mi hermano Javier Camargo: Olga Camargo, bailadora, Ricardo Camargo, músico. Las hijas de mi hermano Ernesto Camargo: Yeni Camargo y Marelis Lucía, bailadoras y cantadoras. La hija de mi sobrino, Jaime Rubiano Camargo, cantadora. Mis hijas Natali y Daniela son cantadoras, me han acompañado como coristas en conciertos $y$ en mis diferentes trabajos musicales. Mejor dicho, a mí por donde me cojan me sale la cantadora, la bailadora y la compositora ( $M$. Camargo, comunicación personal, junio, 14 de 2017).

Si bien la grandeza de Cayetano Camargo, y todo su legado, se tornan inmensos en lo que hoy es la vida artística de Martina, resulta paradójico cómo se autodescribe en la letra del tema Perepe, el cual Martina Camargo interpreta en su producción Paisaje en tambora.
A juicio de Martina, su padre era un hombre sencillo, campesino, a quien no le interesaban ni los reconocimientos ni la fama, era un ser del campo, dicharachero, juguetón y de un humor creativo y repentista, al que en casa llamaban "Perepe".

Lo que sucede -explica Martina-es que mi papá a todo le sacaba gracia, y él se ponía a hablar con sus nietas y nietos, a decirles que tenía una cosa, que tenía ganado, finca, tierras, riquezas, pero la verdad era que mi papá fue muy humilde, que nos enseñó el valor de la educación, que mientras unos hijos estudiaban, otros trabajaban para ir sacando un nuevo bachiller, o nuevo profesional como son mis hermanos y hermanas, pero todo en la casa fue con mucho sacrificio, mi papá enfrentaba las adversidades con dignidad, $y$ al momento de componer Perepe, se burla de sí mismo y de su faceta llena de humor que tanta gracia nos hacía (M. Camargo, comunicación personal, enero, 24 de 2018).

Aquí su letra:

Dicen que Perepe tiene/trapiche y cañaveral/ mentiroso quien lo dice/ Perepe no tiene na'. // ¡Ay caramba tú/ la miel cuajá!/ Perepe no tiene na'//. Dicen que Perepe tiene, / tiene dos camisas, / la una que se pone, / la otra que se quita. Dicen que Perepe tiene, / tiene dos calzones, el uno que se quita, / y el otro que se pone. Dicen que Perepe tiene, / tiene dos zapatos, / el uno que se pone, / y el otro no hace caso. Dicen que Perepe tiene, / tiene dos sombreros, / el uno es liberal, / y el otro es conservero.

Según cuenta Martina, la vida cultural de San Martín de Loba está llena de ricas expresiones culturales que se insertan en las celebraciones religiosas. Es el caso de la novena de Navidad, la que se realiza en San Martín en nueve diferentes calles del pueblo, con rituales religiosos y festivos, a ritmo de tambora. 
En la tradición de los villancicos, también se puede apreciar la creación de cuadros vivos, representaciones teatrales fijas de escenas de la Biblia, o vivencias cotidianas, que exigen un proceso creativo permanente y una disposición hacia el disfrute de las celebraciones.

Por todo ello, a Martina Camargo hay que reconocerla como un ser de vitalidad cultural, que desde niña acogió la tradición como su esencia y un legado que debe continuar:

Mi papá -cuenta Martina- siempre estuvo presente en todas esas actividades culturales, preparando villancicos y los cantos de tambora en la calle de El Carmen, que fue donde yo nací. Cuando mi papá ya estaba viejito, que no pudo seguir con esas actividades, eso fue cuando cumplió ochenta años, yo asumí las responsabilidades de organizar las novenas callejeras, haciéndome así cargo de su legado y su tradición (M. Camargo, conversación personal, junio, 27 de 2018).

Si bien llevar ese legado ha sido algo inherente a su formación, más adelante, con las dinámicas de la tarimización de la cultura, que se da como movimiento silencioso en todas las regiones del Caribe colombiano a través de festivales tradicionales, Martina Camargo se muestra como autoridad y figura sobresaliente en la difusión de las vivencias culturales de su región.

Así en 1988 -refiere Martina-, con la guía de mi padre Cayetano, decidimos armar un grupo que se llamó Aires de San Martín. Ese año me subo por primera vez a una tarima a concursar en el Festival de la Tambora. Ganamos el primer lugar en la modalidad de canción inédita, con el tema Las olas de la mar, compuesta por mi padre, Igualmente, el grupo gana el primer lugar en canto tradicional, riqueza folclórica, y las parejas de baile en veteranos y pareja infantil. Mejor dicho, ganamos todo (M. Camargo, conversación personal, noviembre 9 de 2017).
Luego de esos momentos de triunfo y reconocimiento, llega un hito dramático en la vida de Martina Camargo, el asesinato de su esposo en hechos violentos en la ciudad de Bucaramanga, en 1991. Un hecho al que Martina prefiere no referirse.

Martina se abrió paso con sus dos hijas pequeñas, para seguir adelante con su trabajo musical y un pequeño negocio de calzado y ropa que comenzó con uno de sus hermanos en la zona, dada la conexión comercial que siempre ha existido entre la Región de Loba, o todo el sur de Bolívar, con la ciudad de Bucaramanga.

A mediados de los años 90, tras las investigaciones del musicólogo barranquillero Guillermo Carbó, la difusión de la música de tambora se expande a otros lares. Se suman también la producción de un álbum doble bajo el título Bailes Cantados en Colombia, al cuidado de Carbó, en los que Martina Camargo, al igual que su padre, Cayetano, tienen varios temas. Ese hecho marcó el comienzo de la difusión de los aires de tambora y la expansión de la carrera musical hacia el resto del país y el exterior.

A pesar del relato fluido y coherente sobre su carrera y su éxito, ella misma asegura que no todo ha sido maravilloso, dada la presencia constante de actores armados en su territorio, que transformaron su vida y transformaron la manera de vivir esas prácticas culturales que se hacían de manera libre cuando no existía conflicto armado en la zona:

Aquí hemos sufrido - establece Martina-, aqui estuvo la guerrilla, los paramilitares estuvieron con su horror y su odio hacia la población. La gente tuvo que salir de sus fincas, olvidándose de lo que se hace alli en el campo. Mi hermano Álvaro tuvo que abandonar las tierras, porque eran tierras que tenían oro, lo amenazaron de muerte $y$ todas esas tierras de mi padre se perdieron, se malvendieron, así pasó con mucha gente cercana, que tuvo que venirse desplazada 
para la ciudad... A hacer qué, a sufrir, a padecer, porque su tierra es su manera de vivir, de subsistir (M. Camargo, conversación personal, junio 12, 2018).

En el discurso que está por fuera de las letras de sus canciones, Martina se muestra clara, directa, con las prevenciones que ella misma advierte, porque reconoce que a pesar de las desmovilización de los paramilitares (2003-2006) y la firma del acuerdo de paz con la guerrilla de las FARC en 2016, sabe que la violencia no ha cesado, que aún circulan por el río y en sus pueblos actores ilegales que hacen que la tranquilidad y la expresión no sea plena:

Si bien se habla mucho de la violencia, de los paramilitares $y$ de todas esas fuerzas, $y$ de acciones terribles como masacres $y$ tomas de pueblos en las que se ha comprobado la presencia de actores del Estado, yo como cantadora sé que tengo una misión con nuestro canto, porque el canto, los cantos de todas las cantadoras son formas de resistencia, porque nuestra cultura ha sido resistente y por eso estoy aquí, con mis nuevas canciones que cuentan el paisaje, su gente, su río.

En su discurso, puede entenderse la decisión de no hacer letras ligadas al conflicto, por lo menos de manera explícita; parece entenderse que para ella el hecho de que sus cantos reafirmen realidades y experiencias que se alejan de las temáticas de violencia se presenta como una manera de reafirmar su tradición cultural.

Para Martina es tarea del arte repeler cualquier forma de violencia, cualquier forma que atente contra las vivencias de un pueblo en el campo, en su río. Para ella su canto es coherencia y sus constantes grabaciones así lo expresan.

La cultura -concluye Martina-es la mejor forma de llamar la atención de los jóvenes, es mostrarles otros caminos, como me los mostró mi padre a mí, para que se olviden de las armas, del conflicto, de la muerte, porque si nos encaminamos más hacia la cultura, la paz vendrá de inmediato, es el camino seguro hacia la paz, el mejor camino para llegar a la paz es el arte y la cultura (M. Camargo, conversación personal, junio 12, 2018).

Aunque resulte simple, su coherencia, permanencia y constancia en el canto tienen su origen en una frase pronunciada por su padre tiempo antes de morir: "Martina, nunca dejes de cantar" (M. Camargo, conversación personal, noviembre 9, 2017); eso ella no lo olvida, ha seguido guiada por la memoria de su padre, por la gente de San Martin de Loba, por ese folclor que tanto quiere y con el que ha hecho resistencia a esa violencia que ha vivido desde que tiene memoria.

Tanto el caso de Martina como el de Grilbin Revel se uno a otros compositores y cantantes de la región que pueden contar también su relación con el conflicto armado. En San Martín de Loba está la señora Delcy Gil, hija de Casildo Gil, uno de los más grandes tamboreros y compositores de la región. En Barranco de Loba, está Ángel María Villafañe, un compositor que es también un gran escultor y artesano. En conjunto, son voces que han hecho de su vida cultural la manera de confrontar las adversidades y han dejado en las letras de sus cantos los testimonios de la tragedia que el conflicto generó en sus territorios. 


\section{Referencias}

Abello Vives, A (coordinador). (2013). La savia del desarrollo. Bolívar: Universidad de Girona, Cátedra Unesco de Políticas Culturales, Universidad Tecnológica de Bolívar.

Carbó Ronderos, G. (1998). La tambora: Musique de tradition orale en Colombie. Tesis doctoral, París 4.

Centro Nacional de Memoria Histórica. (2014). Nuevos escenarios de conflicto armado y violencia. Bogotá.

Centro Nacional de Memoria Histórica. (2013). Los orígenes, las dinámicas y el crecimiento del conflicto armado. Informe general del Centro Nacional de Memoria Histórica. Bogotá.

Rivas Lara, D. (2015-2016). Conversación personal con Grilbin Revel.

Rivas Lara, D. (2017-2018). Conversación personal con Martina Camargo.

\section{Videos y discografía disponi- ble en internet}

Música de Grilbin Revel: https://open.spotify. com/album/5YmyXCyAtLpMQQGSdfRxeM

Video Grilbin Revel: https://www.youtube. com/watch?v=ZTV9KBUN65A

Música de Martina Camargo. Cantos ancestrales de Guamanga, Karibona World Music (2013).

Martina Camargo. Paisaje Divino, Karibona

World Music - Martina Camargo (2018)

Martina Camargo. Perepe, video https://www. youtube.com/watch?v=tHC7cC9rrTM 